\title{
Dialysis Arteriovenous Fistula Access for Arterial Interventions: A Forbidden or Forgotten Access
}

A 59-year-old female presented with liver cirrhosis secondary to nonalcoholic steatohepatitis and end-stage renal disease on hemodialysis through left arm brachiocephalic arteriovenous fistula (AVF). She was diagnosed with multinodular hepatocellular carcinoma in segment VIII requiring transarterial chemoembolization. However, due to her refractory thrombocytopenia, the procedure was performed after accessing the venous outflow of the left brachiocephalic fistula to minimize the risk of access-site bleeding [Figure 1]. Selective transarterial chemoembolization was done via a 5-Fr sheath and using drug-eluting beads (100-300 $\mu$ ) loaded with $75 \mathrm{mg}$ doxorubicin [Figure 2].

At the end of the procedure, fistulogram showed juxta-anastomotic stenotic lesion, which was treated with plain balloon angioplasty. Adequate hemostasis was achieved using purse-string suture [Figure 3]. The patient resumed successful dialysis sessions through fistula following the procedure.

As alternative for femoral access, few studies have shown less bleeding and vascular complications with the radial access for arterial intervention in coagulopathic patients or on full oral anticoagulation. This case shows that arterial interventions might be performed safely and effectively through dialysis AVF approach.

\section{Declaration of patient consent}

The authors certify that they have obtained all appropriate patient consent forms. In the form the patient(s) has/have given his/her/ their consent for his/her/their images and other clinical information to be reported in the journal. The patients understand that their names and initials will not be published and due efforts will be made to conceal their identity, but anonymity cannot be guaranteed.

This is an open access journal, and articles are distributed under the terms of the Creative Commons AttributionNonCommercial-ShareAlike 4.0 License, which allows others to remix, tweak, and build upon the work non-commercially, as long as appropriate credit is given and the new creations are licensed under the identical terms.

For reprints contact: reprints@medknow.com

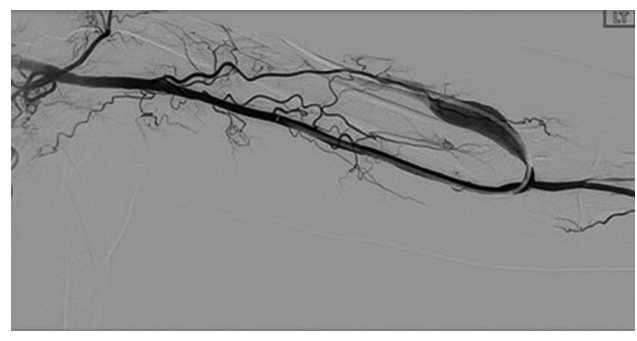

Figure 1: Digital subtraction angiography image showing vascular sheath in the brachial artery

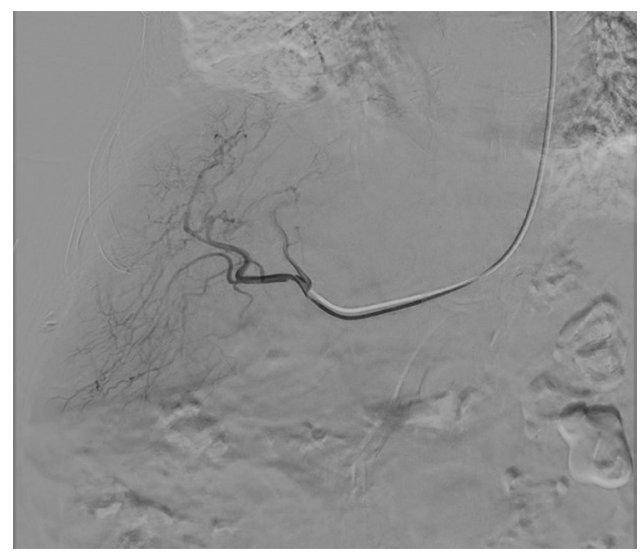

Figure 2: Digital subtraction angiography image showing selective catheterization in the right hepatic artery during transcatheter arterial chemoembolization

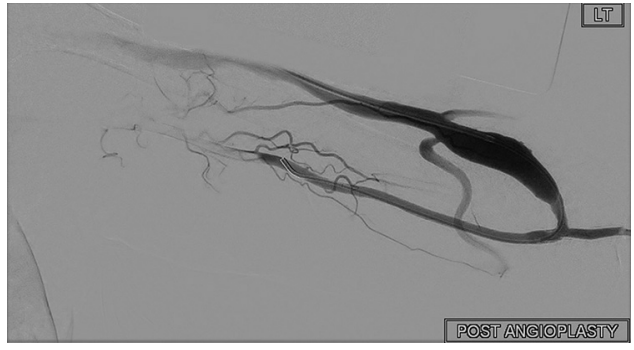

Figure 3: Digital subtraction angiography of the left brachiocephalic fistula postangioplasty at the end of the procedure showing improvement in the morphology of the fistula

Financial support and sponsorship

Nil.

\section{Conflicts of interest}

There are no conflicts of interest.

How to cite this article: Alanazi NA, Altolub MS, AlHendi ND, Al Zahrani YA, Arabi M. Dialysis arteriovenous fistula access for arterial interventions: A forbidden or forgotten access. Arab J Intervent Radiol 2018;2:94.

\section{Naif Abdulaziz \\ Alanazi ${ }^{1,2}$, Mohammed Saeed Altolub ${ }^{1,2}$, Nasser D. AlHendi ${ }^{1}$, Yousof A. \\ Al Zahrani, Mohammed Arabi ${ }^{1}$}

${ }^{1}$ Department of Medical Imaging, Division of Vascular and Interventional Radiology, King Abdulaziz Medical City, ${ }^{2}$ Department of Medical Imaging, College of Medicine, King Saud Bin Abdulaziz University for Health Sciences, Riyadh, Saudi Arabia

Address for correspondence: Dr. Yousof A. Al Zahrani, Department of Medical Imaging, Division of Vascular and Interventional Radiology, King Abdulaziz Medical City, Ministry of National Guard Health Affairs, Riyadh 11426, Saudi Arabia.

E-mail:yousof1403@hotmail. com

Access this article online

Website: www.arabjir.com

DOI: 10.4103/AJIR.AJIR_17_18

Quick Response Code:

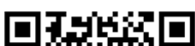

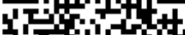

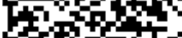
oftrat 